\title{
Immunohistochemical localization of inhibin and activin subunits, activin receptors and Smads in ovarian endometriosis
}

\author{
YASUSHI MABUCHI $^{1}$, MAREO YAMOTO $^{2}$, SAWAKO MINAMI $^{1}$ and NAOHIKO UMESAKI ${ }^{1}$ \\ ${ }^{1}$ Department of Obstetrics and Gynecology, Wakayama Medical University, School of Medicine, \\ 811-1 Kimiidera Wakayama 641-0012; ${ }^{2}$ Department of Obstetrics and Gynecology, \\ Wakayama Rosai Hospital, Japan Labour Health and Welfare Organization, \\ 435 Koya Wakayama 640-8435, Japan
}

Received August 31, 2009; Accepted October 19, 2009

DOI: 10.3892/ijmm_00000308

\begin{abstract}
We previously reported that activin A, not inhibin, was localized to endometrial tissues, and that the endometrium might be a major source of activin A during the menstrual cycle, using an immunohistochemical method. However, there are few detailed reports concerning the expression of inhibin subunits, activin receptors and Smad proteins in the ectopic endometrial tissues of endometriosis. In this study, our purpose was to evaluate the immunohistochemical localization of inhibin $\alpha_{-}, \beta \mathrm{A}$-subunits, activin $\mathrm{A}$, activin receptor, and Smad proteins in ovarian endometriosis. Tissue samples from ovarian endometriosis were obtained from 13 women. Normal endometrial tissues were obtained during the proliferative phase from 5 premenopausal women without endometriosis who were undergoing a hysterectomy for the treatment of uterine cervical intraepithelial neoplasia 3 . We examined the immunohistochemical localization of inhibin/activin $\alpha-$, ßA-subunit, activin A, activin receptors types IA, IB, IIA, IIB, Smad2, Smad3 and Smad4 using an avidin-biotin-peroxidase complex technique. No immunostaining for the $\alpha$-subunit of inhibin was observed in ovarian endometriosis and the normal endometrium. Positive immunostaining for the BA-subunit of inhibin, activin A, activin receptors types IA, IB, IIA, IIB, Smad2, Smad3 and Smad4 was observed in ovarian endometriosis and the normal endometrium. In conclusion, these results suggest that activin $\mathrm{A}$, but not inhibins, is produced by ovarian endometriosis and the normal endometrium, and that the activin signal transduction system exists in both ovarian endometriosis and the normal endometrium.
\end{abstract}

Correspondence to: Dr Yasushi Mabuchi, Department of Obstetrics and Gynecology, Wakayama Medical University, School of Medicine, 811-1 Kimiidera Wakayama 641-0012, Japan E-mail: booyan@wakayama-med.ac.jp

Key words: inhibin, activin, activin receptor, Smad, endometrium, endometriosis

\section{Introduction}

Endometriosis is defined by the presence of endometrial tissues outside the uterus, and is associated with pelvic pain and infertility. Although it is not malignant, endometriosis exhibits cellular proliferation and invasion, and angiogenesis. The pathogenesis of endometriosis still remains unknown. Among numerous substances related to this disease, growth factors are thought to be associated with the development of endometriosis (1), although it is unclear whether they simulate the ectopic endometrial cells, carried by retrograde menstruation or are formed by the metaplastic change of peritoneal mesothelial cells to endometrial ones.

Activins and inhibins belong to the transforming growth factors (TGF)- $\beta$ superfamily (2) and are involved in the regulation of cell growth and differentiation in various kinds of tissues $(3,4)$. Activins and inhibins are dimeric glycoproteins which are isolated from ovarian follicular fluid. Activins are composed of two homologous $\beta$-subunits, and three isoforms, activin $\mathrm{A}(\beta \mathrm{A} / \mathrm{\beta A})$, activin $\mathrm{B}(\beta \mathrm{B} / \mathrm{B})$, and activin $\mathrm{AB}(\beta \mathrm{A} / \mathrm{BB})$, have been identified. Inhibins consist of an $\alpha$-subunit that is linked to a $\beta$-subunit by disulfides, and two forms, inhibin A $(\alpha / \beta A)$ and inhibin $B(\alpha / \beta B)$, have been characterized (5). Activins stimulate the secretion of follicle-stimulating hormone (FSH) from the anterior pituitary gland, whereas inhibins inhibit FSH secretion.

Activin and TGF- 3 ligands bind to ligand-specific receptors, and yet the actions of both growth factors are mediated through the same cytoplasmic signaling components, Smads (6-9). Activin initially binds to an activin type II receptor (ActR IIA or ActR IIB) with high affinity and specificity. Following its binding, the complex recruits the second (type I) receptor (ActR IA or ActR IB) to form an activin type I-II receptor complex. This union promotes phosphorylation at a serine or threonine type I receptor which results in the phosphorylation of two possible receptor-regulated cytoplasmic coactivators (R-Smad2 and R-Smad3), which then interact with the common Smad (co-Smad4) (10-13). The phosphorylated, activated Smad 2/4 or 3/4 complex translocates into the cell nucleus where they play a prominent role in the transcription of activin or TGF- $\beta$ responsive genes (12). Inhibitory Smads (I-Smad6 and 7) block the phosphorylation 
of R-Smads by preventing their association with the type I receptor in the cell cytoplasm, to inhibit additional Smad signaling (12,14).

The signaling pathway of inhibin is less clearly understood. There are neither specific receptors isolated, nor specific threonine/serine kinases identified from genomic searches (15). Recently, Lewis et al (16) reported that the association of inhibin with an accessory binding protein (Bglycan, the so called TGF- $\beta$ receptor type III) promoted inhibin binding to ActR II, and thus this association was a very potent antagonist of activin binding and action.

We previously reported that activin A, not inhibin, was localized to endometrial tissues, and that the endometrium might be a major source of activin A during the menstrual cycle, using an immunohistochemical method (17). Moreover, Luo et al (18) reported that the endometrium expressed Smad3, Smad4 and Smad7 mRNAs and proteins, and that the Smads were localized to the epithelial and stromal cells with cytoplasmic/nuclear localization, using RT-PCR, Western blot analysis, and immunohistochemistry. The authors also reported that TGF- $\beta$ increased Smad mRNA and protein expression and translocation of Smad3 into the nucleus in cultured endometrial cells. However, there are few detailed reports concerning the expression of inhibin subunits, activin receptors and Smad proteins in the ectopic endometrial tissues of endometriosis. In the present study, we examined the immunohistochemical localization of inhibin $\alpha-$, $\beta A$-subunit, activin A, activin receptors, and Smad proteins in normal endometrial tissues and in ovarian endometriosis.

\section{Materials and methods}

Materials. Tissue samples from the ovarian endometriosis were obtained from 13 women who were admitted to Wakayama Medical University Hospital from 1997 to 2003. The ages of the patients with endometriosis ranged from 24 to 49 years

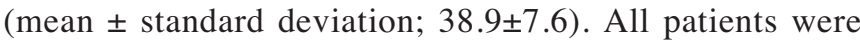
classified as stage III or IV endometriosis according to the revised American Fertility Society classification of endometriosis (19). The diagnosis was confirmed by laparotomic and histological examinations of the endometriotic lesions. Normal endometrial tissues were obtained during the proliferative phase from 5 premenopausal women without endometriosis who were undergoing a hysterectomy for the treatment of uterine cervical intraepithelial neoplasia (CIN) 3 . The ages of the patients without endometriosis ranged from 31 to 43 years (mean \pm standard deviation; 38.2 \pm 4.9 ).

This project was approved by the committee of investigations involving human subjects of the Wakayama Medical University School of Medicine. Informed consent was obtained from each patient after the purpose and nature of the study had been fully explained.

Immunohistochemistry. The antibodies against inhibin/activin $\alpha$ and ßA-subunits were purchased from Serotec (Oxford, UK). The monoclonal antibodies were directed against synthetic peptides that correspond to amino acids 1-32 of the $\alpha$-subunit and $82-114$ of the $B A$-subunit of the $32-\mathrm{kDa}$ inhibin $\mathrm{A}$. The monoclonal antibody against activin A was prepared as described previously (17). The mouse monoclonal antibodies against activin receptors IA, and IIB and the goat polyclonal antibodies against activin receptors IB, and IIA were purchased from R\&D systems (Minneapolis, MN). The antibodies against activin receptors IA, IB, IIA, and IIB were directed against the recombinant human activin receptors IA, IB, IIA, and IIB extracellular domain. The mouse monoclonal antibody against Smad4 and the goat polyclonal antibodies against Smad2 and Smad3 were purchased from Santa Cruz Biotechnology (Santa Cruz, CA). The monoclonal antibody against Smad4 was directed against peptides that correspond to amino acids 1-552 representing the full-length Smad4 of human origin. The goat polyclonal antibodies against $\mathrm{Smad} 2$ and $\mathrm{Smad} 3$ were directed against peptides mapping within the amino terminal domain of Smad2 and Smad3 domain of human origin.

Tissues from the normal endometrium and ovarian endometriosis were fixed in formalin, embedded in paraffin, and cut into $5 \mu \mathrm{m}$ sections. Immunohistochemical procedures were performed via the avidin-biotin-peroxidase complex technique using a Vectastain ABC kit (Vector Laboratories, Burlingame, CA). Briefly, tissue sections were deparaffinized, rehydrated in a graded ethanol series, and washed with $0.05 \mathrm{~mol} / \mathrm{l}$ phosphate buffer, $\mathrm{pH}$ 7.4. The sections were incubated for 30 min with $3 \% \mathrm{H}_{2} \mathrm{O}_{2}$ in phosphate buffer to quench endogenous peroxidase activity and were washed 3 times for $5 \mathrm{~min}$ each in phosphate buffer containing $0.3 \%$ Triton X-100 (Sigma Chemical Co., St. Louis, MO). Sections were incubated for $30 \mathrm{~min}$ at room temperature with $20 \%$ normal horse serum for inhibin $\alpha$ - and BA-subunits, activin receptors IA, IIB Smad4, normal goat serum for activin A, or normal rabbit serum for activin receptor IB, IIA Smad2, Smad3 to block nonspecific binding. Tissue sections were incubated with the primary antibody for $1 \mathrm{~h}$ at room temperature, followed by $16 \mathrm{~h}$ at $4^{\circ} \mathrm{C}$. Each primary antibody was used for analysis at a final concentration of $1 \mu \mathrm{g} / \mathrm{ml}$ ( $\alpha$-subunit, activin A), $2 \mu \mathrm{g} / \mathrm{ml}$ (ßA-subunit), $10 \mu \mathrm{g} / \mathrm{ml}$ (activin receptor IB), $20 \mu \mathrm{g} / \mathrm{ml}$ (activin receptor IA, IIA, IIB, Smad3, $\mathrm{Smad} 4)$, and $5 \mu \mathrm{g} / \mathrm{ml}(\mathrm{Smad} 2)$. Tissue sections were then washed with $0.05 \mathrm{~mol} / 1$ phosphate buffer and incubated with biotinylated horse antibodies against mouse $\operatorname{IgG}$ for $\alpha^{-}$, ßA-subunits, activin receptor IA, IIB and Smad4, with biotinylated goat antibodies against mouse $\operatorname{IgM}$ for activin A, or with biotinylated rabbit antibodies against goat IgG for activin receptor IB, IIA, Smad2 and Smad3 for $30 \mathrm{~min}$ at room temperature. The antigen-antibody complexes were visualized with diaminobenzidine as the chromogen after incubation with the avidin-biotin peroxidase complex for $30 \mathrm{~min}$ at room temperature. The sections were counterstained with Meyer's hematoxylin and observed under a light microscope.

For the preparation of negative controls, samples were treated with preimmune sera from mice, rabbits, and goats instead of the primary antibodies at the same dilution, and no immunoreactivity was observed (data not shown).

\section{Results}

Fig. 1 shows the immunolocalization of the inhibin/activin $\alpha-, \beta A-s u b u n i t$, and activin $\mathrm{A}$ in tissues from ovarian endometriosis and the normal endometrium. We did not observe any immunostaining for the $\alpha$-subunit of inhibin (Fig. 1A and B) in the tissues of ovarian endometriosis and normal endo- 

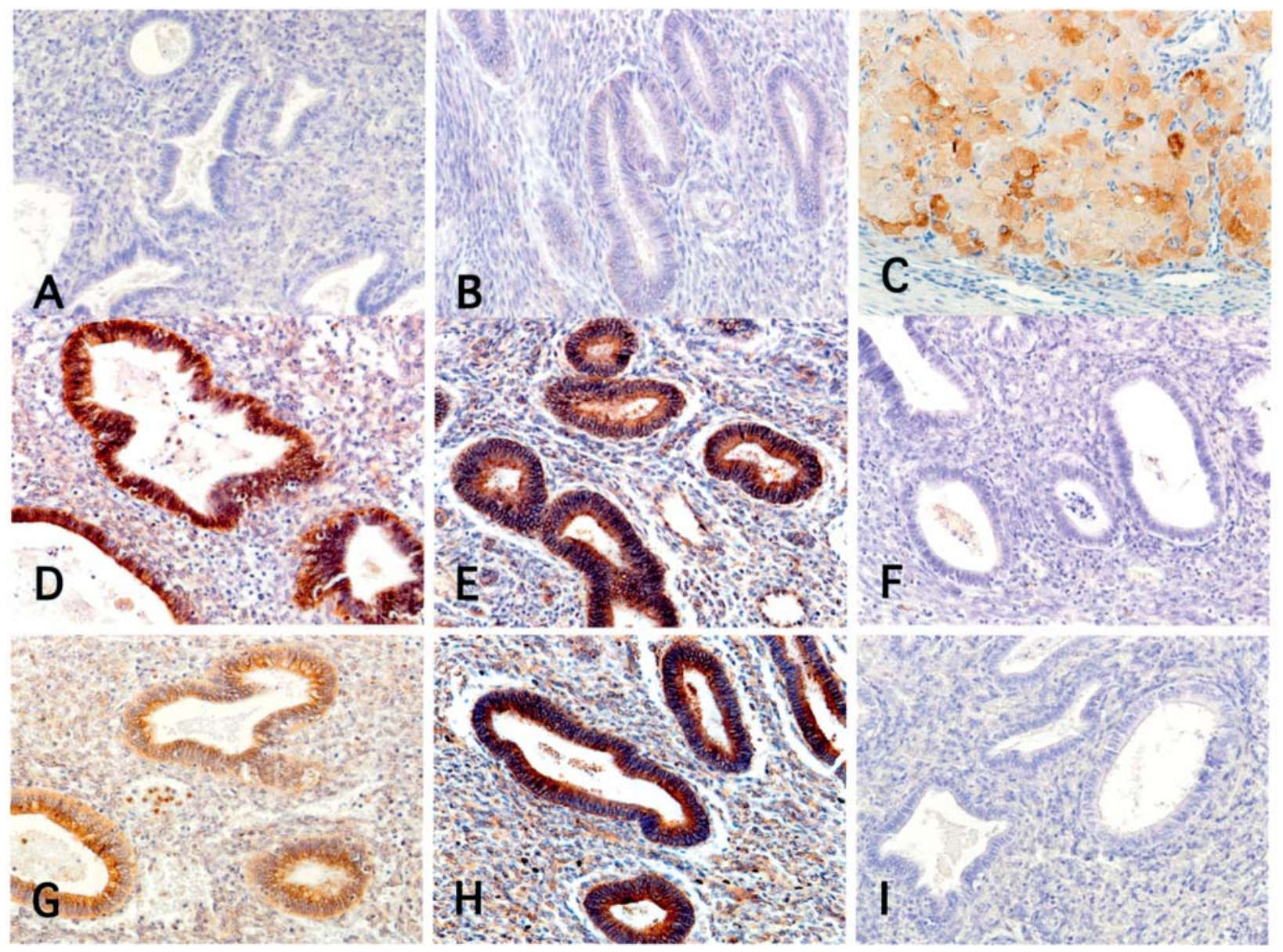

Figure 1. Immunohistochemical localization of inhibin subunits and activin A in ovarian endometriosis and the normal endometrium. Tissues stained brown are positive for immunoreactivity. The nuclei are stained blue. The left and middle panels are ovarian endometriosis (A, D and G) and the normal endometrium in the proliferative phase (B, E and $\mathrm{H}$ ), respectively. Representative sections showing immunostaining for the $\alpha$-subunit (A and B), $\beta$ A-subunit (D and E) and activin A ( $\mathrm{G}$ and $\mathrm{H})$. No immunostaining specific for the $\alpha$-subunit $(\mathrm{A})$ was observed in ovarian endometriosis and the normal endometrium (B). Immunostaining for the BA-subunit ( $\mathrm{D}$ and $\mathrm{E}$ ) and activin $\mathrm{A}(\mathrm{G}$ and $\mathrm{H}$ ) was evident in the cytoplasm of cells from ovarian endometriosis and the normal endometrium. Positive immunostaining for the $\alpha$-subunit was observed in the luteal cells of the human corpus luteum (C). No immunostaining was observed in ovarian endometriotic tissues treated with a secondary anti-mouse IgG only (F) or a secondary anti-mouse IgM only (I). Original magnification, x200.

metrium. However, with the antibodies against BA-subunit (Fig. 1D and E) and activin A (Fig. 1G and H), we observed strong immunoreactive staining of the cytoplasm in all cases of ovarian endometriosis and the normal endometrium. As for positive controls, we immunostained corpora lutea using antibodies against the $\alpha$ - and $\beta A$-subunits and we observed strong immunostaining for the $\alpha$-subunit (Fig. 1C) and BA-subunit (data not shown) in the luteal cells. No immunostaining was observed in the normal endometrium and ovarian endometriosis tissues treated with secondary antimouse IgG only (Fig. 1F) or secondary antimouse IgM only (Fig. 1I).

Fig. 2 shows the immunolocalization of the activin receptors, type IA (Fig. 2A and B), type IB (Fig. 2C and D), type IIA (Fig. 2E and F) and type IIB (Fig. $2 \mathrm{G}$ and $\mathrm{H}$ ) in tissues from ovarian endometriosis and the normal endometrium. In ovarian endometriosis, we observed positive immunoreactive staining in the cell cytoplasm and with the antibodies against activin receptors, type IA in 11 out of 13 cases (Fig. 2A), type IB in 12 out of 13 cases (Fig. 2C), type IIA in 8 out of 13 cases (Fig. 2E) and IIB in all cases (Fig. 2G). In the normal endometrium, we observed positive immunoreactive staining in the cytoplasm and cell surface with the antibodies against activin receptors, type IA in all cases (Fig. 2B), type IB in 3 out of 5 cases (Fig. 2D), type IIA in all cases (Fig. 2F) and IIB in 4 out of 5 cases (Fig. 2H).

Fig. 3 shows the immunolocalization of the Smad2 (Fig. 3A and B), Smad3 (Fig. 3C and D), and Smad4 (Fig. 3E and $\mathrm{F}$ ) proteins in tissues from ovarian endometriosis and the normal endometrium. In the normal endometrium, we observed positive immunoreactive staining in the cytoplasm and nucleus with antibodies against Smad2 in 4 out of 5 cases (Fig. 3B), Smad 3 and Smad4 in all cases (Fig. 3D and F). In the tissues from ovarian endometriosis, we observed positive immunoreactive staining in the cytoplasm and nucleus with antibodies against $\mathrm{Smad} 2$ in 5 out of 13 cases (Fig. 3A), Smad3 in 4 out of 13 cases (Fig. 3C) and Smad4 in 9 out of 13 cases (Fig. 3E).

\section{Discussion}

In the present study, immunostaining with antibodies against the BA-subunit and activin A was observed intracytoplasmically in epithelial cells from the normal endometrium and ovarian endometriosis. We did not detect any immunostaining for the 

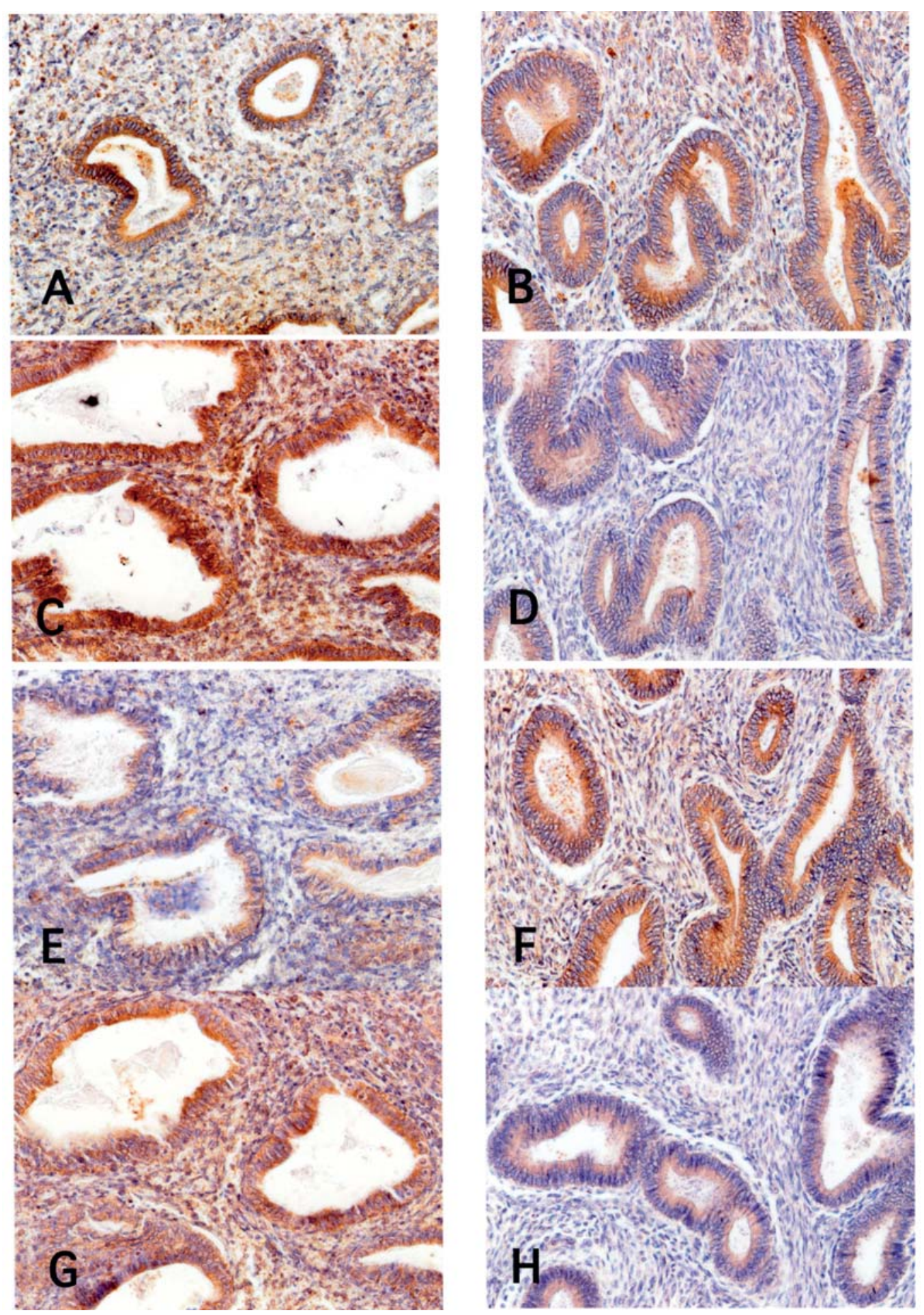

Figure 2. Immunohistochemical localization of activin receptor types IA, IB, IIA and IIB in ovarian endometriosis and the normal endometrium. The left panels are ovarian endometriosis (A, C, E and G) and the right panels are the normal endometrium (B, D, F and $\mathrm{H}$ ). Representative sections showing immunostaining for activin receptors, type IA (A and B), type IB (C and D), type IIA (E and F) and type IIB ( $\mathrm{G}$ and $\mathrm{H})$. Immunostaining for activin receptor types IA, IB, IIA and IIB was evident in the cytoplasm and the cell surface of ovarian endometriosis and the normal endometrium. Original magnification, x200.

$\alpha$-subunit in the normal endometrium or ovarian endometriosis. The stroma, on the other hand, showed faint immunostaining for the BA-subunit and activin A. These findings suggest that activin $\mathrm{A}$, but not inhibins, is produced in the normal endometrium and in ovarian endometriosis.

Indeed, vascular endothelial growth factor (VEGF) is a potent angiogenic factor involved in both physiological and pathological angiogenesis. The eutopic endometrium of women with endometriosis had higher expression levels of VEGF mRNA than those of women without endometriosis (20), and the peritoneal fluid from women with endometriosis contained significantly greater amounts of VEGF than those from women without endometriosis (21). In addition, hepatocyte growth factor (HGF), which was initially recognized as 

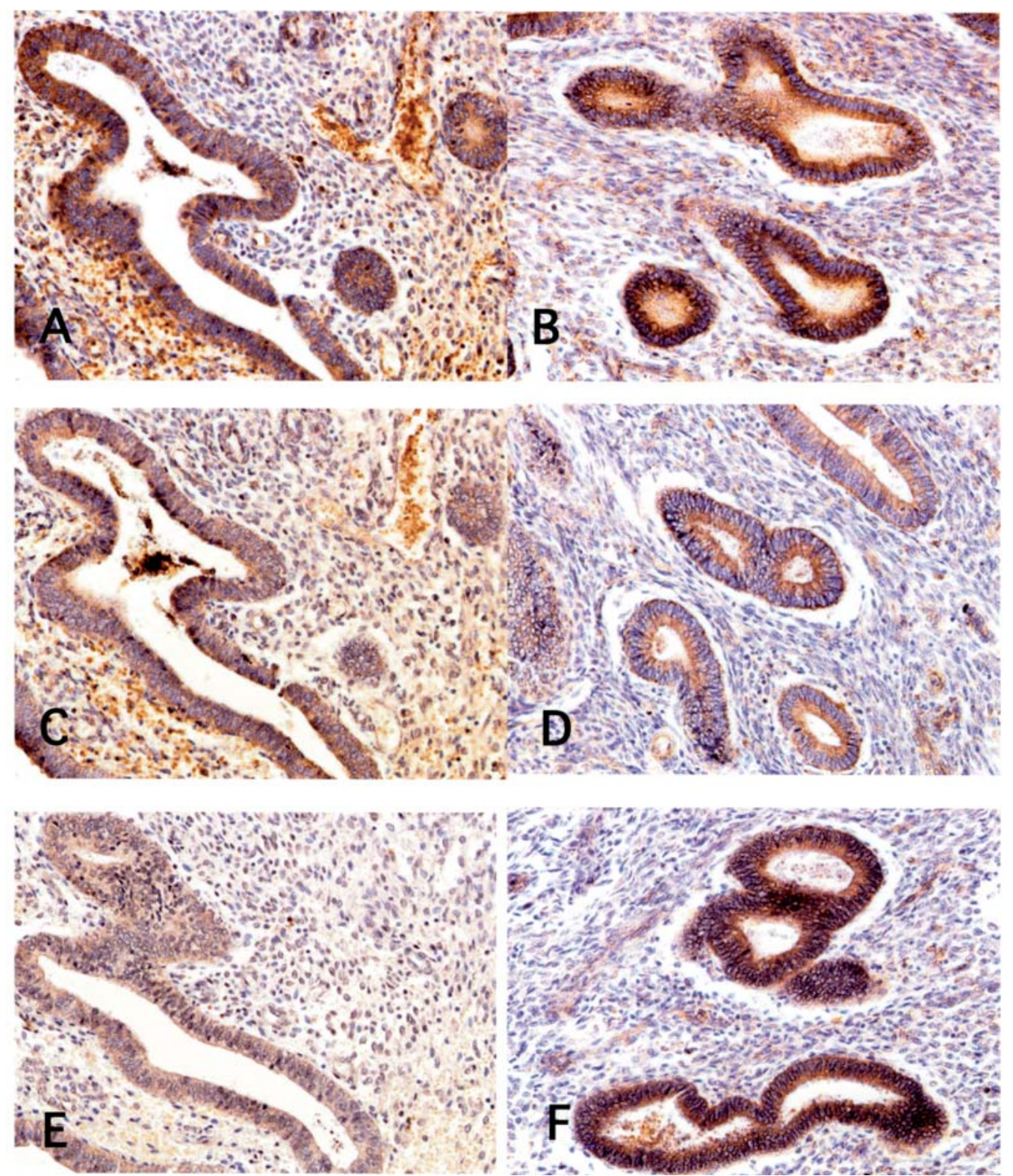

Figure 3. Immunohistochemical localization of Smad2, Smad3, and Smad4 in ovarian endometriosis and the normal endometrium. The left panels are ovarian endometriosis (A, C and E) and the right panels are the normal endometrium (B, D and F). Representative sections showing immunostaining for Smad2 (A and B), Smad3 (C and D) Smad4 (E and F). Immunostaining for Smad2, Smad3 and Smad4 was evident in the cytoplasm and nucleus of cells from ovarian endometriosis and the normal endometrium. Original magnification, x200.

a strong mitogen for hepatocytes, has recently been thought to have mitogenic effects on various kinds of tissues. The expression of HGF and its receptor, c-Met, were significantly higher in the eutopic endometrium of women with endometriosis than in that of women without endometriosis (22). The HGF concentrations in the peritoneal fluid from women with stage III/IV endometriosis were also significantly higher than those from women without endometriosis (23).

Matzuk et al (24) demonstrated that inhibin can act as a novel secreted tumor suppressor protein with specificity for gonadal sex cord stromal tumors in their inhibin deficiency animal study. In addition, Shikone et al (25) demonstrated that activin A can act as an autocrine growth factor that stimulates the proliferation of cell lines derived from the gonadal stromal tumors in inhibin $\alpha$-subunit knockout mice. In humans, we previously reported that activin A, not inhibins, was localized to the endometrial tissues and that the endometrium might be a major source of activin A during the normal menstrual cycle, using an immunohistochemical method (17). Reis et al (26) reported that inhibin $\alpha$ - and BAsubunits were localized in the epithelial and stromal components of ovarian endometrioma using immunohistochemistry and that the mRNAs of inhibin $\alpha$ - and BA-subunit were expressed in endometriotic cells using RT-PCR. The authors (26) also demonstrated that the inhibin A and activin A concentrations in the cystic fluid of ovarian endometriosis were significantly higher than in the peripheral blood using a two-site enzyme immunoassay. On the other hand, Florio et al (27) reported that cultured endometriotic cells expressed the mRNA of inhibin $\alpha_{-}^{-}, \beta A-, \beta B$-subunits, and activin receptors types II and IIB, and that the inhibin A, inhibin B and activin A concentrations of the peritoneal fluid were not significantly 
different between healthy women and patients with endometriosis. Cobellis et al (28) also reported that no significant difference was observed in the peritoneal fluid activin A concentrations between patients with endometriosis and healthy controls. Oosterlynck et al (29) reported that the concentration of TGF- $\beta$, which shares the signaling component, Smad with activin, in the peritoneal fluid from women with endometriosis was significantly higher than that from women without endometriosis.

The current study demonstrated that, in the normal endometrium and in ovarian endometriosis, immunostaining with antibodies against activin receptors types IA, IB, IIA and IIB was observed in the cytoplasm and cell surface and that the immunohistochemical localization of Smad2, Smad3 and Smad4 was in the cytoplasm and nucleus of the cells. These findings suggest that normal endometrial and ovarian endometriotic tissues are a target of the autocrine/paracrine effects of activin A and that the activin signal transduction system is functioning in the normal endometrium and ovarian endometriosis. Moreover, the activin signaling components may influence the implantation of the normal endometrium into the intraperitoneal cavity and the subsequent formation of ovarian endometriotic lesions.

To our knowledge, there are no detailed data concerning Smad in endometriosis. However, it has been reported that Smad proteins are suppressive against cell proliferation in various tissues, including cancer tissues. Smad4 gene alteration, which leads to tumor progression, is the most prevalent, especially in pancreatic cancers $(30,31)$. Although mutations in the Smad2 gene have been detected in colorectal cancers (32), their frequency was far less than that of Smad4. Jeruss et al (33) reported that there were significant correlations in breast cancer specimens between a decrease in nuclear Smad3 abundance and high tumor and architecture grades, larger tumor size, and hormone receptor negativity. On the other hand, Moustakas and Heldin (34) reported that pathways which are independent of Smad proteins exist as part of the cell proliferation signaling by TGF- $\beta$. It may be possible that nonSmad substances mediate the cell proliferation signals from activin.

In our present study, although there was no significant difference between the immunostaining intensities of the nuclear Smad2, Smad3 and Smad4 from ovarian endometriosis and those from normal endometrium, the number of positive cases of Smad2 (5 out of 13 cases) and Smad3 (4 out of 13 cases) in ovarian endometriosis was smaller than those of Smad2 (4 out of 5 cases) and $\operatorname{Smad} 3$ (5 out of 5 cases) in the normal endometrium. Although the effect of Smad on endometrial cells is not well understood, the lower number of Smad immunopositive cases in ovarian endometriosis as compared with the normal endometrium may suggest the following theories. First, Smad has a suppressive effect on the proliferation of endometrial cells, and thus Smad expression is impaired during the formation of endometriotic lesions. Second, non-Smad signaling pathways exist in ectopic endometrial cells.

In conclusion, we observed immunoreactive staining with antibodies against the $\beta A$-subunit and activin $\mathrm{A}$ in the normal endometrium and ovarian endometriosis. It is suggested that activin $\mathrm{A}$, but not inhibins, is produced by the normal endometrium and ovarian endometriosis. We also demonstrated the immunolocalization of activin receptors types IA, IB, IIA, IIB, Smad2, Smad3 and Smad4 in the normal endometrium and ovarian endometriosis, which suggested that an activin signal transduction system is present in the normal endometrium and ovarian endometriosis.

\section{Acknowledgements}

This work was supported by JSPS Grant-in-Aid for Scientific Research 20791157. We thank Dr Y. Eto (Central Research Laboratories, Ajinomoto Co., Inc., Kawasaki, Japan) for donating the monoclonal antibody against recombinant human activin $\mathrm{A}$.

\section{References}

1. Gazvani R and Templeton A: Peritoneal environment and angiogenesis in the pathophysiology of endometriosis. Reproduction 123: 217-226, 2002.

2. Massague J: Transforming growth factor beta family. Annu Rev Cell Biol 6: 597-641, 1990.

3. Mason AJ, Hayflick JS, Ling N, et al: Complementary DNA sequences of ovarian follicular fluid inhibin show precursor structure and homology with transforming growth factor- $\beta$. Nature 318: 659-663, 1985.

4. Lapolt PS and Hsueh AJW: Moleculer basis of inhibin production and action. Mol Cell Neurosci 2: 449-463, 1991.

5. Vale W, Rivier C, Hsueh A, et al: Chemical and biological characterization of the inhibin family of protein hormones. Recent Prog Horm Res 44: 1-34, 1988.

6. Nakao A, Imamura $\mathrm{T}$, Souchelnytskyi $\mathrm{S}$, et al: TGF- 3 receptormediated signaling through Smad2, Smad3, and Smad4. EMBO J 16: 5353-5362, 1997.

7. Whitman M: Smads and early developmental signaling by the TGF- 3 superfamily. Genes Dev 12: 2445-2462, 1998.

8. Yue $\mathrm{J}$ and Mulder KM: Requirement of RAS/MAPK pathway activation by transforming growth factor- $\beta 1$ production in a Smad-dependent pathway. J Biol Chem 275: 30765-30773, 2000.

9. Yue J and Mulder KM: Transforming growth factor- $\beta$ signal transduction in epithelial cells. Pharmacol Ther 91: 1-34, 2001.

10. Woodruff TK and Mather JP: Inhibin, activin and the female reproductive axis. Annu Rev Physiol 57: 219-244, 1995.

11. Risbridger GP, Schmitt JF and Robertson DM: Activin and inhibins in endocrine and other tumors. Endocr Rev 22: 836-858, 2001.

12. Attisano L and Tuen Lee-Hoeflich S: The Smads. Genome Biol 2: 3010.1-3010.8, 2001.

13. Shi Y, Hata A, Lo RS, Massague J and Pavletich NP: A structural basis for mutational inactivation of the tumour suppressor Smad4. Nature 388: 87-93, 1997.

14. Massague J: TGF-ß signal transduction. Annu Rev Biochem 67: 753-791, 1998

15. Pangas SA and Woodruff TK: Activin signal transduction pathways. Trends Endocrinol Metab 11: 309-314, 2000.

16. Lewis KA, Gray PC, Blount AL, et al: Betaglycan binds inhibin and can mediate functional antagonism of activin signaling. Nature 404: 411-414, 2000.

17. Otani T, Minami S, Kokawa K, Shikone T, Yamoto M, Nakano R Immunohistochemical localization of activin $\mathrm{A}$ in human endometrial tissues during the menstrual cycle and in early pregnancy. Obstet Gynecol 91: 685-692, 1998.

18. Luo $\mathrm{X}, \mathrm{Xu} \mathrm{J}$ and Chegini $\mathrm{N}$ : The expression of Smads in human endometrium and regulation and induction in endometrial epithelial and stromal cells by transforming growth factor- $\beta$. J Clin Endocrinol Metab 88: 4967-4976, 2003.

19. American Fertility Society: Revised American Fertility Society classification of endometriosis. Fertil Steril 43: 351-352, 1985.

20. Tan XJ, Lang JH, Liu DY, Shen K, Leng JH and Zhu L: Expression of vascular endothelial growth factor and thrombospondin-1 mRNA in patients with endometriosis. Fertil Steril 78: 148-153, 2002 
21. McLaren J, Prentice A, Charnock-Jones DS and Smith SK Vascular endothelial growth factor (VEGF) concentraions are elevated in peritoneal fluid of women with endometriosis. Hum Reprod 11: 220-223, 1996.

22. Khan KN, Masuzaki H, Fujishita A, Kitajima M, Sekine I and Ishimaru T: Immunoexpression of hepatocyte growth factor and c-Met receptor in the eutopic endometrium predicts the activity of ectopic endometrium. Fertil Steril 79: 173-181, 2003.

23. Osuga Y, Tsutsumi O, Okazaki R, et al: Hepatocyte growth factor concentrations are elevated in peritoneal fluid of women with endometriosis. Hum Reprod 14: 1611-1613, 1999.

24. Matzuk MM, Finegold MJ, Su JG, Hsueh AJ and Bradley A: Alpha-inhibin is a tumour-suppressor gene with gonadal specificity in mice. Nature 360: 313-9, 1992.

25. Shikone T, Matzuk MM, Perlas E, et al: Characterization of gonadal sex cord-stromal tumor cell lines from inhibin-alpha and p-53 deficient mice: the role of activin as an autocrine growth factor. Mol Endocrinol 8: 983-985, 1994.

26. Reis FM, Blasio AM, Florio P, Ambrosini G, Loberto CD and Petraglia F: Evidence for local production of inhibin A and activin A in patients with ovarian endometriosis. Fertil Steril 75: 367-373, 2001

27. Florio P, Luisi S, Vigano P, et al: Healthy women and patients with endometriosis show high concentration of inhibin A inhibin B, and activin A in peritoneal fluid throughout menstrual cycle. Hum Reprod 13: 2606-2611, 1998.
28. Cobellis L, Reis FM, Luisi S, et al: High concentrations of activin $\mathrm{A}$ in the peritoneal fluid of women with epithelial ovarian cancer. J Soc Gynecol Investig 11: 203-206, 2004.

29. Oosterlynck DJ, Meuleman C, Waer M and Koninckx PR: Transforming growth factor- $\beta$ activity is increased in peritoneal fluid from women with endometriosis. Obstet Gynecol 83: 287-292, 1994

30. Miyaki M and Kuroki T: Role of Smad4 (DPC4) inactivation in human cancer. Biochem Biophys Res Commun 306: 799-804, 2003.

31. Hahn SA, Schutte M, Hoque AT, et al: DPC4, a candidate tumor suppressor gene at human chromosome 18q21.1. Science 271: 350-335, 1996.

32. Eppert K, Scherer SW, Ozcelik H, et al: MADR2 maps to $18 \mathrm{q} 21$ and encodes a TGF- $\beta$ regulated MAD-related protein that is functionally mutated in colorectal carcinoma. Cell 86: 543-552, 1996.

33. Jeruss JS, Sturgis CD, Rademaker AW and Woodruff TK: Down-regulation of activin, activin receptors, and Smads in high-grade breast cancer. Cancer Res 63: 3783-3790, 2003.

34. Moustakas A and Heldin CH: Non-Smad TGF-beta signals. J Cell Sci 118: 3573-3584, 2005. 